\title{
The Effect of Land Degradation on Farm Size Dynamics and Crop-Livestock Farming System in Ethiopia: A Review
}

Assemu Tesfa ${ }^{*}$, Shigdaf Mekuriaw

Andassa Livestock Research Center, Bahir Dar, Ethiopia.

Email: ${ }^{*}$ assemu.tesfa@yahoo.com

Received November $27^{\text {th }}, 2013$; revised December $27^{\text {th }}$, 2013; accepted January $4^{\text {th }}, 2014$

Copyright (C) 2014 Assemu Tesfa, Shigdaf Mekuriaw. This is an open access article distributed under the Creative Commons Attribution License, which permits unrestricted use, distribution, and reproduction in any medium, provided the original work is properly cited. In accordance of the Creative Commons Attribution License all Copyrights (C) 2014 are reserved for SCIRP and the owner of the intellectual property Assemu Tesfa, Shigdaf Mekuriaw. All Copyright @ 2014 are guarded by law and by SCIRP as a guardian.

\section{ABSTRACT}

Ethiopia is among the poorest countries in which poverty, land and resource degradation appear to feed off each other. The irony is that Ethiopia is a country with high biodiversity and distinctive ecosystems and the natural resource base is critical to the economy and the livelihood of a high percentage of the population. Being the owner of varying agro ecology, the country's agricultural production system had practiced for decades with a maximum potential. However, because of the presence of interrelated problems, the productivity had not sustained as its potential. From the interrelated problems, land degradation takes the first and challengeable problem in many countries. Land degradation refers to a temporary or permanent decline in the productive capacity of the land, or its potential for environmental management as a result; the long-term biological and environmental potential of the land has been compromised. Land degradation in the Ethiopian highlands (i.e. areas above 1500 m.a.s.l.) has been a concern for many years and is a great threat for the future that requires great effort and resources to ameliorate. It had adverse effect on lowering of livestock production by shrinking grazing land, the fertile soil types were washed and the grazing land was dominantly covered by unpalatable pastures and grasses which had low nutritive value and fertility for crop-livestock production system. In other cases, degradation induces farmers to convert land to lower-value uses; for instance, cropland converted to grazing land, or grazing lands converted to shrubs or forests. Equitable and secure access to land is a critical factor for the rural poor, especially livestock owners, who depend on agriculture and animal-related activities for their livelihood. Having secure access to land for agriculture and pastoral activities reduces their vulnerability and enhances their opportunities to invest in land for agriculture and livestock activities. Historical patterns of feudal ownership of land followed by government ownership and despite policy change uncertain status of land ownership. These land distribution and ownership patterns coupled with continuous fragmentations and degradation disrupt the balance between crop, livestock, and forest production. These things nowadays enforce Ethiopian farmers to put more land into crop production than working on livestock sector. Livelihoods are complex, dependent on animal and crop production based on land and water resources, with emerging market opportunities. And from year to year, the size of farms is getting minimized because of land degradation and segmentations, and these make a change in farm size dynamics and farming shift. Currently, there is a great scenario towards the land policy pattern and agricultural production system, which is the backbone of the country's economy. Therefore, the aim of this paper is to review the effect of land degradation on farm size dynamics and crop-livestock production since the impact of these things is not well measured.

\section{KEYWORDS}

Crop-Livestock Farming System; Farmers; Farm Size Dynamics; Land Degradation

\footnotetext{
${ }^{*}$ Corresponding author.
} 


\section{Introduction}

In Ethiopia, 85\% of the population are directly supported by the agricultural economy [1,2]. However, the productivity of that economy is being seriously eroded by unsustainable land management practices both in areas of food crops and in grazing lands [2]. Land degradation represents a loss of Natural Capital, the value to society of land, water, plant, and animal resources, and the direct contribution to primary production in crop agriculture, livestock rising, fishing, and related industries such as commodity marketing and processing. Indicators include reduced yield, change in land use, change in crops, abandonment of fields, and altered livestock mixes and patterns of grazing [3].

Land degradation in the Ethiopian highlands (i.e. areas above 1500 m.a.s.l.) has been a concern for many years. Soil erosion, nutrient depletion and deforestation are common, but little has been done to determine their impact on productivity. Land degradation, which refers to the deterioration or total loss of the productive capacity of the soils for present and future use [4], is a great threat for the future and it requires great effort and resources to ameliorate. The major causes of land degradation in Ethiopia are the rapid population increase, severe soil loss, deforestation, low vegetative cover, unbalanced crop and livestock production [5], unsustainable arable farming techniques, the use of dung and crop residues for fuel, and overstocking of grazing lands under Natural Conditions [4]. On less frequent, but dramatic occasions, land degradation forces population displacement and hundreds of thousands hectares of land has to be abandoned each year for being too degraded for cultivation or even grazing.

Loss of arable land due to soil erosion is a widespread phenomenon in the highlands, which account for about $45 \%$ of Ethiopia's total land area and about $66 \%$ of the total land area of Amhara Region as well as on steep hillsides, and soil losses of exceeding $200 \mathrm{t}$ /ha per year have been recorded. The threat is credible as about $90 \%$ of the population of the Amhara Region lives in the highlands and $90 \%$ of the regularly cropped land is found there. Soil erosion by water is the dominant form of erosion. The areas that are severely affected can be found in Wag Hemra and North Wello followed by North and South Gonder, eastern parts of South Wello and northern parts of North Shewa zones. Gullies are a frequent and permanent phenomenon everywhere in the region [1].

\section{Land Degradation and Its Economic Loss}

All physical and economic evidence shows that loss of land resource productivity is an important problem in Ethiopia and that with continued population growth the problem is likely to be even more important in the future. In the highlands of Ethiopia, the area of most intense population density, the area of greatest livestock density and the area of greatest land degradation, recorded measurements of soil loss by water erosion range from 3.4 to 84.5 tons per ha per year with a mean of 32.0 tons/ha/year [2]. As evaluated and measured by [2], the major costs that the country, Ethiopia, pays because of land degradation includes costs of nutrients lost with top soil erosion, lost production due to nutrient and soil loss, costs of forest removal, and loss of livestock carrying capacity. The current scenario towards the land policy pattern that is implemented by the government, the agricultural production system, the fertility, shrinkage and productivity of arable and grazing lands which had decline from time to time; and its potential cause to declining of agricultural productivity and continuing food insecurity and rural poverty initiates this paper with the aim of reviewing the effect of land degradation on farm size dynamics and crop-livestock farming system in Ethiopia.

\section{Land Degradation and Its Potential Causes}

Land degradation is one of the major causes of low and in many places declining agricultural productivity and continuing food insecurity and rural poverty in Ethiopia. Although there has been a great deal of effort to address land degradation problems in Ethiopia, these have failed to reverse the downward spiral in much of the worst affected areas of the country. Part of the reason for this has been the promotion of practices and technologies that were not well suited to the conditions facing farmers in their particular location, and hence not profitable or excessively risky [2]. Recent research has shown that other factors such as population pressure and small farm sizes, land tenure insecurity, land redistribution, limited access to credit, limited education, and others also inhibit adoption of sustainable land management practices in some areas [6].

Land degradation is increasing in severity and extent in many parts of the world, with more than $20 \%$ of all cultivated areas, $30 \%$ of forests and $10 \%$ of grasslands undergoing degradation [7]. Millions of hectares of land per year are being degraded in all climatic regions. It is estimated that 2.6 billion people are affected by land degradation and desertification in more than a hundred countries, influencing over 33\% of the earth's land surface [8].

The immediate causes of land degradation are inappropriate land use that leads to degradation of soil, water and vegetative cover and loss of both soil and vegetative biological diversity, affecting ecosystem structure and functions [9]. Degraded lands are more susceptible to the adverse effects of climatic change such as increased temperature and more severe droughts [10]. 
On the other hand, the [11] stressed that land degradation is complex and involves the interaction of changes in the physical, chemical and biological properties of the soil and vegetation. The complexity of land degradation means its definition differs from area to area, depending on the subject to be emphasized. Around 73\% of rangelands in dry land areas are currently degraded, together with $47 \%$ of marginal rain-fed croplands and a significant percentage of irrigated croplands [12]. Thirty-one per cent of the continent's pasture lands and 19\% of its forests and woodlands also are classified as degraded [13]. Overgrazing has long been considered the primary cause of degradation in Africa but it is now thought that rainfall variability and long-term drought are more important determinants [12].

Land degradation is especially widespread in SubSaharan Africa, affecting 20\% - 50\% of the land and some 200 million people [9]. Furthermore, Snel and Bot [9] stated that land degradation is also widespread and severe in Asia and Latin America as well as in other regions of the globe. It not only reduces farm productivity affecting livelihood and regional economies, it also leads to reduced biodiversity and stream sedimentation affecting water quality, storage and marine resources.

Little reliable data is available on the extent of land degradation in Africa. The presence of gullies and sand dunes, of degraded forests and grazing lands are obvious, although the effects of sheet erosion and declining soil fertility are less noticeable. The wealth of Africa depends on her ability to conserve and manage her land resources [10]. It is a well known fact that soil degradation not only results in decreased food production but also in droughts, ecological imbalance and consequent degradation of the quality of life. Berry and his colleagues [3] indicates that in many parts of the world, production systems and their environments have come under much stress, due to many causes including changing land tenure regimes, population growth, climatic fluctuations, overuse of natural resources especially in marginal environments, and a lack of appropriate policies or financial resources for sustainable development. Root causes of these problems include historical and changing patterns of land ownership and government control, low levels of investment in agriculture and animal husbandry, poor rural infrastructure and markets and low levels of technology [3].

\subsection{Land Degradation Effect on Farming Shift}

A number of factors contribute to unsustainable land management in Ethiopia. With steady growth in population, clearing of woodland for agriculture has been a continuous process with an increasing rate in each year; methods of cereal production are conducive to soil loss and dung and crop residues are needed for fuel, reducing their use as fertilizers [2]. Continuous cultivation, with crop rotation was introduced as a management system to maintain favorable soil conditions and satisfactory yields. Recently, rapid population increase, which has resulted in very small holdings, has changed the situation [14]. Excessive pressure on the vegetal cover by animals can be a crucial problem, especially in developing countries where rangelands usually are much more crowded than in the developed world [13].

The report of Steve Wiggins [15] indicated that the farm size changes in Ethiopia during 1977, 1989/92 and 2001/02 was one, 0.5 and 0.75 (approximated) hectares, respectively. Similarly, Bereket Kebede [16] reported that the land holding per household was 0.55 ha. This indicates that the land holdings had changed up and down through the advancements of years, which inturn brings in farming practices shift based on the land resource available in hand.

As erosion reduces crop productivity, the degree of control of erosion declines due to decreasing vegetative cover. Therefore, once crop productivity begins to decline because of soil degradation, land degradation becomes self-perpetuating. Crop yields on severely degraded soil are much lower than those on protected soils because erosion reduces soil fertility and water availability. The NEC [11] study indicates that the plain areas of the highlands in Gojam, Awi and the south-eastern parts of the region have a moderate soil erosion hazard. However, as these are currently the most productive and surplus-producing areas of the region, due to the ample rainfall and gentler slopes, these estimates should not be interpreted as though land degradation is not problematic but, rather, as an indication for remedy.

\subsection{Land Degradation Effect on Crop-Livestock Farming System}

Ethiopia is divided into different agro ecological zones delineated by biophysical conditions [17] which are significantly influenced by altitude, which ranges from -155 to +4000 meters above sea level. Rain fed agriculture dominates in Ethiopia. However, rainfall distribution and intensity vary spatially, tending to decrease from southwest to northeast [18] as cited by [19]. These rainfall patterns affect crop and livestock production and contribute to volatility in food prices, which ultimately affects overall economic development [13]. Subsistence farming is a typical feature of agriculture in Ethiopia. The midlands and highlands are dominantly characterized as mixed farming systems where livestock and crop production are almost equally important and highly integrated. In the lowlands, pastoral systems dominate and agro-pastoral systems are only practiced in a few areas. Single cropping is the norm but double cropping is practiced along rivers and as alley cropping in some parts of the county (e.g., in Bale highlands) [19]. 
In the Northern Highlands of Ethiopia, integrated croplivestock production is the dominant form of agricultural production within the smallholder farms. Feed availability and quality are serious constraints to livestock production in Ethiopia in general, and in its Northern Highlands in particular [14]. Mixed crop-livestock production system had also practiced in the Western part of the country in which livestock production is subsistenceoriented and is an important component of the mixed farming system and is well integrated with crop production [20]. All around the globe, the agricultural systems in use by farmers today are different from those used some time ago. In this process of transition, in the SubSaharan African (SSA) countries, agricultural systems are showing disequilibrium dynamics; outflows particularly of nutrients, from the system exceeding inflows into the system [14]; about 50\% of all cropland in Ethiopia is affected by soil degradation.

Stagnating or declining food crop and livestock production, natural resources degradation and poverty are interrelated problems in less favored areas, such as the Northern Highlands of Ethiopia [14]. Smallholder farmers manage crop and animal production in an integrated way, to maximize returns from their limited land and capital, minimize production risk, diversify sources of income, provide food security and increase productivity. Ethiopia has the largest livestock population in Africa [17], of which about $75 \%$ (estimated at 45 million TLU) is concentrated in the highlands, where smallholders practice livestock and crop production within the same farm unit. Integrated, also called mixed, crop-livestock farming is practiced to diversify household income sources through crop production, sales of meat and milk, to proved of draught power and manure production and to serve as capital asset (savings account; investment) [14]. In the low potential cereal zone with low market access and a low population density, an appropriate strategy may be to increase the productivity of the mixed crop-livestock system by improved management of grazing lands and woodlots, and integrated soil nutrient management on cultivated land. The supply of inputs such as fertilizer, farm machinery and credits are very low. The balance between crop, livestock, and forest production is disturbed, and the farmer is forced to put more land into crop production. For environmentally and socially sustainable development, there is an urgent need to promote awareness and understanding of the interdependence of natural, socioeconomic, and political systems at local and national levels [5].

Nomadic herders, grazing animals on arid and semiarid lands, are particularly vulnerable to drought, since it depletes their most precious assets: their livestock herds. In northern and eastern Kenya, for example, the drought of 1992 decimates the livestock herds of pastoral com- munities, forcing herders to sell cheaply to local traders [13]. Already, degraded steep slopes are grazed continuously and are not allowed to regenerate. This phenomenon is observed especially in South Gonder, and North and South Wello zones, where wet and marshy (riparian) areas, which were used previously for grazing, are increasingly being drained for cropping [1]. The cattle industry has been an integral part of the land degradation debate. It has received most of the blame for the perceived degradation problem, but at the same time has most to lose, because declining primary productivity translates to declining secondary production [21]. Agricultural practices fundamentally influence soil characteristics over time. Farmers improve soil nutrient levels by adding manure or fertilizer; reduce acidity by adding lime; and optimize water availability through drainage or irrigation [22].

\subsection{Land Degradation Effect on Farm Size Dynamics}

Land tenure has, over the years, been one of the most important institutions that affect land management decisions in Westrern parts of Ethiopia. Theoretically, tenure security and investment in land, and hence better management of land including use of appropriate technologies are positively related. Land tenure security has been poor generally under all the three political regimes in recent periods: the feudal, Derg and current regimes [23].

In the drier parts of Africa, millions of hectares of grazing land and rangeland are also threatened with degradation in the arid north, the semi-arid south, the Sudano-Sahelian countries and in the drier parts of Cameroon, Ethiopia, Kenya and Nigeria. The 1983-85 and recent droughts killed huge numbers of livestock there, with the result that good breeding stock was lost and the structural balance of herds distorted. Nevertheless, the herds are now recovering, but within five or ten years the trend of increasing overgrazing could be re-established until the next drought reduces livestock numbers again. The rangeland itself has been changed for the worse, with many of the perennial grasses being replaced by nutritionally poorer annual grasses. This has permanently impaired the rangeland's potential for recovery and decreased its carrying capacity. As the vegetation has been removed or reduced, the wind has also winnowed out the small amount of silt that the soil contains, reducing its ability to retain moisture. When it does rain, the chances of the range recovering are correspondingly reduced. Sustainable rural production is critical for the future of the economy. However, land degradation remains as major problem in the highlands. Past remedial measures have focused on terracing but have only begun to address the basic issues. The need for a more integrated rural economy is a critical component of the problem as is the 
uncertainty in many areas of the ownership context of land management issues [3].

\section{Conclusion and the Way Forward}

Reflections of different literature indicate that Land degradation decrease in area cultivated, reduced crop yield and cumulative effect on low productivity of livestock. In most countries, the main causes of land degradation were soil erosion and nutrient depletion resulting in the formations of gully. The FAO report recommends to mitigate Land Degradation by restoring damaged land through soil conservation, silvopastoralism, better management of grazing systems and protection of sensitive areas. Success in fighting Land Degradation requires an improved understanding of its causes, impact, degree and acquaintance with climate, soil, water, land cover and socioeconomic factors. Using an appropriate strategy to increase the productivity of the mixed crop-livestock system, improved management of grazing lands and woodlots, integrated soil nutrient management on cultivated land, application of long term strategies for land (environmental) conservation (coordination with different projects) and adopting a new policy and strategies to the natural resource improvement strategy (implementing a one-to-five farmers arrangement) should get attention in the countries long term strategies like Growth and Transformation Plan (GTP).

\section{REFERENCES}

[1] A. Woldu, "Dairy Marketing System Study Amhara National Regional State Head of Government Office,” Bahir Dar, 2004.

[2] L. Berry, "Land Degradation in Ethiopia: Its Extent and Impact," Commissioned by the GM with WB Support, 2003.

[3] L. Berry, J. Olson and D. Campbell, “Assessing the Extent Cost and Impact of Land Degradation at the National Level; Overview: Findings and Lessons Learned,” 2003.

[4] POPIN, United Nations Population Information Network, “Population and Land Degradation,” 1995.

[5] G. Taddese, "Land Degradation: A Challenge to Ethiopia," US National Library of Medicine National Institutes of Health, 2001.

[6] Environmental Economics Policy Forum of Ethiopia, "Poverty and Land Degradation in Ethiopia: How to Reverse the Spiral?” Concept Note International Food Policy Research Institute (IFPRI) and Wageningen University and Research Center (WUR), 2005.

[7] Z. G. Bai, D. L. Dent, L. Olsson and M. E. Schaepman, "Global Assessment of Land Degradation and Improvement 1,” ISRIC, Wageningen, 2008.

[8] C. R. Adams and H. Eswaran, "Global Land Resources in the Context of Food and Environmental Security,” In: S. P. Gawande, Ed., Advances in Land Resources Manage- ment for the 20th Century, Soil Conservation Society of India, New Delhi, 2000, 655 p.

[9] M. Snel and A. Bot, "Draft Paper: Suggested Indicators for Land Degradation Assessment of Drylands,” FAO, Rome, 2003.

[10] L. R. Oldeman, R. T. A. Hakkeling and W. G. Sombroek, "World Map on the Status of Human Induced Soil Degradation, with Explanatory Note (Second Revised Edition),” ISRIC, Wageningen, UNEP, Nairobi, 1991.

[11] Netherlands Engineering Consultants, “Tekeze River Basin Integrated Development Master Plan Project (TRBIDMPP): Land Degradation and Soil Conservation,” Second Phase Report, Volume-ENV1, Consultant's Report to the Commission for Sustainable Agriculture and Environmental Rehabilitation for Amhara Region (CoSAERAR), Bahir Dar, 1997, 101 p.

[12] United Nations Economic Commission for Africa, "Sustainable Agriculture and Environmental Rehabilitation Programme: Household Level Socio-Economic Survey of the Amhara Region,” Produced by the Co-Operative Endeavours of the Amhara Regional Council and UNECA. UNECA, Addis Ababa, Vol. 1, 1996, 298 p.

[13] Food and Agriculture Organization, "Land and Environmental Degradation and Desertification in Africa,” 2005.

[14] A. Abegaz, "Feed Resources, Livestock Production and Soil Carbon Dynamics in Teghane,” Northern Highlands of Ethiopia, 2005.

[15] S. Wiggins, “Farm Size Dynamics,” Overseas Development Institute (ODI), 2003.

[16] B. Kebede, "Land Reform, Distribution of Land and Institutions in Rural Ethiopia: Analysis of Inequality with Dirty Data,” 2006.

[17] Ministry of Agriculture, “Agro-Ecological Zones of Ethiopia on 1:2,000,000 scale,” Natural Resource Management and Regulatory Department, MoA, Addis Ababa, 2000.

[18] W. H. Cheung, G. B. Senay and A. Singh, "Trends and Spatial Distribution of Annual and Seasonal Rainfall in Ethiopia,” International Journal of Climatology, Vol. 28, No. 13, 2008, pp. 1723-1734. http://dx.doi.org/10.1002/joc.1623

[19] Agricultural Water Management, "Ethiopia Situation Analysis,” 2009.

[20] B. Duguma, A. Tegegne and B. P. Hegde, "Smallholder Livestock Production System in Dandi District, Oromia Regional State, Central Ethiopia,” Global Veterinaria, Vol. 8, No. 5, 2012, pp. 472-479.

[21] E. B. Barbier, "Modelling Land Degradition in Low-Input Agriculture: The 'Population Pressure Hypothesis' Revised," The 25th International Conference of Agriculture Economists, 16-22 August 2003, Durban.

[22] I. Coxhead and R. Øygard, “Land Degradation,” Copenhagen Consensus, 2008.

[23] B. Nega, B. W. Adene and S. Gebre Sellasie, "Current Land Policy Issues in Ethiopia,” Ethiopian Economic Policy Research Institute, Addis Ababa, 2003. 